WellBeing International

WBI Studies Repository

$6-2000$

\title{
Mixing at Young Ages Reduces Fighting in Unacquainted Domestic Pigs
}

\author{
Anton D. Pitts \\ University of British Columbia \\ Daniel M. Weary \\ University of British Columbia \\ Edmond A. Pajor \\ Purdue University \\ David Fraser \\ University of British Columbia
}

Follow this and additional works at: https://www.wellbeingintlstudiesrepository.org/agobeh

Part of the Animal Studies Commons, Behavior and Ethology Commons, and the Comparative Psychology Commons

\section{Recommended Citation}

Pitts, A. D., Weary, D. M., Pajor, E. A., \& Fraser, D. (2000). Mixing at young ages reduces fighting in unacquainted domestic pigs. Applied Animal Behaviour Science, 68(3), 191-197.

This material is brought to you for free and open access by WellBeing International. It has been accepted for inclusion by an authorized administrator of the WBI Studies Repository. For more information, please contact wbisr-info@wellbeingintl.org.

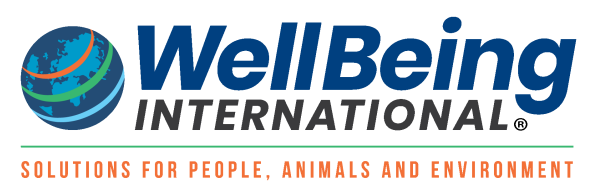




\title{
Mixing at Young Ages Reduces Fighting in Unacquainted Domestic Pigs
}

\author{
Anton D. Pitts ${ }^{1}$, Daniel M. Weary ${ }^{1}$, Edmond A. Pajor ${ }^{2}$, David Fraser $^{1}$ \\ ${ }^{1}$ University of British Columbia \\ ${ }^{2}$ Purdue University
}

\begin{abstract}
KEYWORDS
aggression, pig-agonistic behaviour, social behaviour, mixing

ABSTRACT

Under normal farming practices, piglets from different litters are often mixed around the time of weaning, and a high incidence of fighting and minor injuries often occur. The aim of this experiment was to determine the effect of age on the incidence of fighting in piglets mixed before weaning, at different ages between 5 and 26 days. We found no significant relationship between age and the likelihood that a pair of piglets would fight during the first 75 min after mixing. However, the duration of the first fight observed increased from $101 \pm 38 \mathrm{~s}$ at 5 days to $621 \pm 278 \mathrm{~s}$ at 26 days, mainly because of higher levels of unretaliated harassment and resting during the bouts. Younger pigs also showed $80 \%$ fewer injuries from the fighting. The results suggest some potential welfare advantage to allowing litters to mix at younger ages.
\end{abstract}

\section{Introduction}

In commercial swine production in North America, the weaning of piglets is associated with several animal welfare concerns (Fraser et al., 1998), one of which is the common practice of mixing piglets from different litters. Fighting between newly mixed piglets is common during the first days after weaning and sometimes leads to significant injury, whether mixing occurs at weaning (Friend et al., 1983; Rundgren and Löfquist, 1989), a week after weaning (Algers et al., 1990), or several weeks later (Ewbank and Meese, 1971; Graves et al., 1978; McGlone, 1985).

Under free-ranging conditions, sows will generally seek out a secluded nest location a few days before farrowing, and then spend most of their time in the nest during the first few days post partum. The sow and litter then rejoin the rest of the social group when the piglets reach 10-12 days of age (Jensen and Redbo, 1987). Thus, under natural conditions, piglets may be predisposed to form social bonds with littermates immediately after birth, and with other piglets in the social group at 10-12 days of age.

Work by Scott (1962) has demonstrated the existence of a 'critical period' for the formation of social bonds in young dogs. Plyusnina et al. (1991) found that domestication (selection for domestic behaviour) led to a lengthening of the period of primary socialisation and a delay in the onset of aggressive behaviour in silver foxes. Jensen (1994) found that some, but not all, measures of aggression in domestic pigs were higher at 5 and 9 weeks of age than at 1 week, and Petersen et al. (1989) suggested that formation of social bonds in pigs may be facilitated during a critical period when piglets could be mixed 
with low levels of fighting. Other work on agonistic behaviour in pigs has studied fighting in older piglets, mixed at or after weaning (Ewbank and Meese, 1971; Graves et al., 1978; Friend et al., 1983; McGlone, 1985; Jensen and Yngvesson, 1998). Recent work on alternative housing systems for sows and litters (e.g., Weary et al., 1999) has suggested that agonistic behaviour may be reduced in systems where litters are mixed at younger ages, before weaning, and in the presence of the sow. The present experiment used encounters between pairs of unacquainted, unweaned piglets between 5 and 26 days of age to isolate the effect of mixing age from other differences in these systems (e.g., number of piglets present, size of enclosure, presence/absence of sow, etc)., and to test the hypothesis that piglets are predisposed to socialise at around 12 days of age.

\section{Methods}

\subsection{Subjects and procedure}

Thirty litters were assigned to 15 litter-pairs, each consisting of two litters born within the same $24 \mathrm{~h}$. Each litter-pair contributed four pairs of previously unacquainted piglets, selected based on similar body weights, with each pair of piglets tested on one of $5,12,19$ or 26 days of age.

For each trial, the two piglets were simultaneously placed together in a pen, approximately $120 \times 120 \mathrm{~cm}$ containing a creep feeder and a nipple drinker and in a separate wing from the piglet's home pen. Room temperature was maintained at $28-30^{\circ} \mathrm{C}$. The piglets' behaviour was videotaped using Burle TC-651EA cameras mounted above each pen, a Burle TC-1474 quadrat multiplexer and a Panasonic AG-6730 video recorder. Throughout the trial, the piglets were observed on a closed-circuit monitor from outside the room, and a running tally of the time spent fighting was kept. To minimize any suffering, trials were terminated after $30 \mathrm{~min}$ for any piglets that had spent $5 \mathrm{~min}$ or more fighting (as defined below). The remaining trials were continued until (a) the end of the fighting bout when the cumulative amount of fighting reached $5 \mathrm{~min}$, or (b) $75 \mathrm{~min}$ after the start of the trial, whichever occurred earlier. Preliminary observations indicated that this would provide adequate data without leading to excessive fighting or injury. On commercial farms, fighting among newly mixed pigs is common (up to 10-20 fights per halfhour during the first $4-5 \mathrm{~h}$ after mixing), and individual fights can last up to half an hour (Meese and Ewbank, 1973). Piglets were immediately returned to their dam at the end of the trial. All procedures used in this study were approved by the Animal Care Committee of Agriculture and Agri-food Canada's Centre for Food and Animal Research. Because of equipment failure, eight encounters could not be scored. Sample sizes at each age were 15, 15, 8 and 14 pairs, respectively.

\subsection{Measures}

All behavioural measures were obtained from the videotapes. A fighting bout was defined as a period of frequent biting and close physical contact by the piglets, lasting at least $15 \mathrm{~s}$ and not interrupted by periods without physical contact longer than $60 \mathrm{~s}$. Preliminary observations suggested that these criteria would include virtually all bites and biting attempts by the piglets without counting very short periods of separation as the start of a new bout. Occasionally, at the end of a fight, the piglets remained in contact, but directed their attention to the feeder or the sides of the pen, with no further attempts to bite during the next $60 \mathrm{~s}$. In these cases, the fight was considered to have ended at the last bite or attempted bite.

Within each bout of fighting, four categories of behaviour were scored:

"active fighting": both piglets made frequent attempts to bite the other; "harassment": one piglet bit the other, usually on or behind the neck, but the other did not bite back or manoeuvre into a position from which it could bite back; "resting": piglets remained in physical contact, usually pressing against each other and/or jostling for position, but few ( $<1$ per $5 \mathrm{~s}$ ) if any bites were 
attempted; "no contact": the piglets separated and were not in physical contact for periods shorter than $60 \mathrm{~s}$.

Within each bout, transition times (to the nearest second) between behavioural categories were scored. If less than $5 \mathrm{~s}$ was spent in a category, it was not scored. From these data, the time spent in each category was calculated for each bout. The time elapsed (from the start of the trial) until the total time spent fighting reached 5 min was also calculated.

To quantify the injuries received by the piglets, the number of scratches, bruises or other marks on each piglet was noted before and after each trial. Marks were scored separately for the ears, face, neck and flanks. In the few cases where minor injuries were present at the start of the trial, these were ignored, and the number of new marks that appeared during the trial was recorded. When more than 6-7 marks were present on the same part of the body, resolving individual marks became difficult, and an " 8 " was recorded. The counts for different areas of the body were added together, and totals for the two pigs were averaged to provide a single measure of injury occurring during the encounter.

\subsection{Analysis}

A $\chi^{2}$ test was used to analyze age differences in the proportion of trials in which fighting occurred. Among the trials where fights did occur $(n=26)$, we analyzed the number of scratches appearing on the piglets, the time elapsed before the first fight began, the length of the first bout, and the time spent in each of the four behavioural categories (active, resting, harassment and no contact) during that bout. Among trials where more than one bout was observed $(n=14)$, we also calculated the length of each subsequent bout and the amount of time spent in each behavioural category. Since trial length was variable, we present results for the first bout only, but similar trends were observed for data derived from grouping all fights observed in the encounters. Data on the injuries sustained by the pigs were based on the entire trial; the variation in trial length may reduce the variation in this measure as the amount of fighting was capped, but should not lead to spurious age effects.

Using a general linear model, linear ( $1 d f$ ) and residual non-linear ( $2 d f$ ) age effects on each of the response variables were tested against the residual error. Variables were approximately normally distributed, and no transformations were considered necessary. We also ran the tests after including a term for litter (14 df ) or gender ( $2 d f$; male, female or different) in the model statement. Neither non-linear age, litter nor gender terms significantly improved the fit of any models, so we omitted these terms from the final model.

\section{Results}

Fighting was observed during 26 of the 52 trials. The proportion of trials where fighting occurred ranged from $36 \%$ at 26 days of age to $66 \%$ at 12 days of age (Table 1), but frequencies did not differ significantly among ages $\left(\chi_{3}^{2}=2.88, P=0.4\right)$. At the 3 youngest age, none of the piglets fought for more than $5 \mathrm{~min}$, and all trials lasted a full $75 \mathrm{~min}$. The total time spent fighting during the trials increased from $121 \pm 33 \mathrm{~s}$ at 5 days to $673 \pm 256 \mathrm{~s}$ at 26 days, $\left(F_{1,24}=9.56 ; P=0.005\right.$., and $80 \%$ of trials at 26 days where fighting occurred were interrupted before $75 \mathrm{~min}$. Of the 26 trials in which fights occurred, 12 had only one bout of fighting, and only four had more than two. Since relatively few pigs engaged in multiple fights, we were unable to compare early and late bouts.

The first fight observed was shortest for the 5-day-old piglets (101 s), and increased to $621 \mathrm{~s}$ for the 26day-old pigs $\left(F_{1,24}=7.55 ; P=0.011\right.$, Table 1$)$. On average, more than half of the bout was spent in active fighting, except for the 26 -day-old piglets, who averaged $26 \%$ of the first bout in active fighting and $40 \%$ in 
harassment. While only resting increased significantly in length (GLM: $F_{1,24}=5.74 ; P=0.025$, active fighting $\left(F_{1,24}=3.14 ; P=0.089\right.$. and harassment (GLM: $F_{1,24}=3.22 ; P=0.085$. both showed a nonsignificant tendency to increase with age (Table 1).

Most of the marks observed on the piglets after encounters were relatively mild; a few piglets had broken skin in places, but most of the injuries in this study were sub-surface bruising. The average number observed ranged from 2-3 marks per pig at 5 days to $7-8$ marks per pig at 26 days of age $\left(F_{1,24}=6.55 ; P\right.$ $=0.017 ;$ Table 1 ).

Table 1. Number of trials with and without fighting, length of the first fighting bout, time spent in each behavioural category during the first fighting bout, and number of marks (scratches, bruises, etc.) observed on each pig (mean \pm S.E.M.), shown for the four ages studied.

\begin{tabular}{|lcccc|}
\hline Measure & \multicolumn{4}{c|}{ Piglet age (days) } \\
\cline { 2 - 5 } & $\mathbf{5}$ & $\mathbf{1 2}$ & $\mathbf{1 9}$ & $\mathbf{2 6}$ \\
\hline Trials with fighting & a & 10 & 4 & 5 \\
Trials without fighting & 7 & 5 & 4 & 9 \\
Bout length (s) & 8 & $143 \pm 53$ & $135 \pm 65$ & $621 \pm 278$ \\
& $101 \pm 38$ & & & \\
Time spent & & & $101 \pm 51$ & $160 \pm 67$ \\
Active & $60 \pm 27$ & $81 \pm 28$ & 0 & $257 \pm 226$ \\
Harassment & $10 \pm 6$ & $14 \pm 11$ & $33 \pm 16$ & $199 \pm 113$ \\
Resting & $19 \pm 7$ & $41 \pm 23$ & $2 \pm 2$ & $5 \pm 4$ \\
No Contact & $12 \pm 8$ & $8 \pm 6$ & & \\
Marks (number) & $1 \pm 1$ & $4 \pm 1$ & $5 \pm 3$ & $8 \pm 2$ \\
\hline
\end{tabular}

${ }^{a}$ The number of trials where fighting occurred was the sample size for measures of bout length, time spent in each behavioural category, and number of marks.

\section{Discussion}

Contrary to our original hypothesis, the 12-day-old piglets proved slightly (but not significantly) more likely to fight than younger or older pigs. In agreement with the hypothesis, however, bout length increased with piglet age. While the fraction of the bout spent in active mutual aggression decreased, the total amount of time spent in mutual aggression tended to increase with age. The greatest contributors to the increase in bout length were the large increases in the time spent in harassment and in resting postures. These results are in agreement with previous work (Jensen, 1994) which studied encounters involving unacquainted piglets, and found that 1-week-old piglets were no less likely to fight during their first encounter than were 5- or 9-week-old pigs, but did tend to fight for a shorter time. The youngest piglets in this earlier study also spent a smaller proportion of their fights in spatial configurations associated with a high frequency of reciprocal biting.

This study also found that fewer lesions appeared on the younger piglets after short encounters with previously unknown piglets. This observation could be explained by at least two factors: the younger piglets spent less time fighting, and, being smaller, they may have given less forceful bites which, in turn, would be less likely to lead to visible injury.

These results support the view that piglets have a pre-disposition to tolerate strangers at younger ages, but it is impossible to completely separate the effects of age and space allowance. The younger piglets, 
being smaller, effectively had more room in which to manoeuvre, and this may have affected the agonistic behaviour. Although body-turning was considered to be a submissive behaviour pattern by McGlone (1985), other researchers have suggested that pigs do not have a clear submission signal that prevents further aggression (Meese and Ewbank, 1973; Rushen and Pajor, 1987); hence, piglets may rely instead on escape to end aggressive encounters (Ewbank and Meese, 1971). If escape is the primary method by which a losing piglet avoids further aggression from the winner, the reduction in relative space with increasing piglet size would be expected to lead to a protracted harassment phase at the end of a fight, which may explain both the increased total bout length and the increase in the proportion of the fight spent in harassment. This idea could be tested by mixing pigs in different sizes of pens; pigs mixed in large pens should have shorter fights composed largely of active fighting whereas those mixed in smaller pens should have longer fights with extended periods of unretaliated harassment. Some support for these predictions is provided by Randolph et al. (1981), who found that the number of 'attacks' (non-retaliated) increased with stocking density in growing-finishing pigs, while the number of 'fights' (retaliated) did not.

However, piglet age and space allowance cannot be completely unconfounded, and without independent knowledge of the way in which the piglets evaluate the space available to them, in the context of fighting behaviours, we cannot be certain that the number of pigs per unit surface area is a better measure to hold constant than the length, surface area or weight of pigs per unit of pen surface area.

In practical terms, however, the size of the pens in which young piglets are mixed on commercial farms will not change with piglet age. Our results show that younger (and smaller) piglets have shorter fights after mixing, all else being equal, and that they also sustain fewer injuries from these fights. Whether this is due to the piglets giving fewer bites (as they spent less time fighting) or less forceful bites (as they are smaller and less heavy) than older piglets, it does suggest potential welfare advantages to allowing piglets to encounter non-litter-mates well before being mixed at standard weaning ages of 3-5 weeks.

\section{Acknowledgements}

The experimental work was performed at the Centre for Food and Animal Research, prior to its closure. We thank the director and staff for their help with this and other experiments and in maintaining an excellent environment for research. We thank Cindy Moore for her help in running the experiment and the staff of our research barn for their help and co-operation. This work was partly supported by an NSERC Strategic Grant.

\section{References}

Algers, B., Jensen, P., Steinwall, L., 1990. Behaviour and weight changes at weaning and regrouping of pigs in relation to teat quality. Appl. Anim. Behav. Sci. 26, 143-155.

Ewbank, R., Meese, G.B., 1971. Aggressive behaviour in groups of domesticated pigs on removal and return of individuals. Anim. Prod. 13, 685-693.

Fraser, D., Milligan, B.N., Pajor, E.A., Phillips, P.A., Taylor, A.A., Weary, D.M., 1998. Behavioural perspectives on weaning in domestic pigs. In: Wiseman, J., Varley, M.A., Chadwick, J.P. (Eds.), Progress in Pig Science. Notthingham Univ. Press, Nottingham, pp. 121-140. 
Friend, T.H., Knabe, D.A., Tanksley, T.D., 1983. Behavior and performance of pigs grouped by three different methods at weaning. J. Anim. Sci. 57, 1406-1411.

Graves, H.B., Graves, K.L., Sherritt, G.W., 1978. Social behavior and growth of pigs following mixing during the growing-finishing period. Appl. Anim. Ethol. 4, 169-180.

Jensen, P., 1994. Fighting between unacquainted pigs - effects of age and of individual reaction pattern. Appl. Anim. Behav. Sci. 41, 37-52.

Jensen, P., Redbo, I., 1987. Behaviour during nest leaving in free-ranging domestic pigs. Appl. Anim. Behav. Sci. 18, 355-362.

Jensen, P., Yngvesson, J., 1998. Aggression between unacquainted pigs - sequential assessment and effects of familiarity and weight. Appl. Anim. Behav. Sci. 58, 49-61.

McGlone, J.J., 1985. A quantitative ethogram of aggressive and submissive behaviors in recently regrouped pigs. J. Anim. Sci. 61, 559-565.

Meese, G.B., Ewbank, R., 1973. The establishment and nature of the dominance hierarchy in the domesticated pig. Anim. Behav. 21, 326-334.

Petersen, H.V., Vestergaard, K., Jensen, P., 1989. Integration of piglets into social groups of free-ranging domestic pigs. Appl. Anim. Behav. Sci. 23, 223-236.

Plyusnina, I.Z., Oskina, I.N., Trut, L.N., 1991. An analysis of fear and aggression during early development of behaviour in silver foxes (Vulpes vulpes). Appl. Anim. Behav. Sci. 32, 253-268.

Randolph, J.H., Cromwell, G.L., Stahly, T.S., Kratzer, D.D., 1981. Effects of group size and space allowance on performance and behaviour of swine. J. Anim. Sci. 53, 922-927.

Rundgren, M., Löfquist, L., 1989. Effects on performance and behaviour of mixing 20-kg pigs fed individually. Anim. Prod. 49, 311-315.

Rushen, J., Pajor, E., 1987. Offence and defence in fights between young pigs (Sus scrofa). Aggressive Behav. 13, 329-346.

Scott, J.P., 1962. Critical periods in behavioral development. Science 138, 949-957.

Weary, D.M., Pajor, E.A., Bonenfant, M., Ross, S.K., Fraser, D., Kramer, D., 1999. Alternative housing for sows and litters: 2. Effects of a communal piglet area on pre- and post-weaning behaviour and performance. Appl. Anim. Behav. Sci. 65, 123-135. 